\title{
The $\mathrm{T}$ box regulatory element controlling expression of the class I lysyl-tRNA synthetase of Bacillus cereus strain 14579 is functional and can be partially induced by reduced charging of asparaginyl-tRNA ${ }^{\text {Asn }}$
}

Niall Foy ${ }^{1}$, Brian Jester ${ }^{2}$, Gavin C Conant ${ }^{3}$, Kevin M Devine ${ }^{1 *}$

\begin{abstract}
Background: Lysyl-tRNA synthetase (LysRS) is unique within the aminoacyl-tRNA synthetase family in that both class I (LysRS1) and class II (LysRS2) enzymes exist. LysRS1 enzymes are found in Archaebacteria and some eubacteria while all other organisms have LysRS2 enzymes. All sequenced strains of Bacillus cereus (except AH820) and Bacillus thuringiensis however encode both a class I and a class II LysRS. The lysK gene (encoding LysRS1) of B. cereus strain 14579 has an associated T box element, the first reported instance of potential T box control of LysRS expression.
\end{abstract}

Results: A global study of 891 completely sequenced bacterial genomes identified T box elements associated with control of LysRS expression in only four bacterial species: B. cereus, B. thuringiensis, Symbiobacterium thermophilum and Clostridium beijerinckii. Here we investigate the $\mathrm{T}$ box element found in the regulatory region of the lys $K$ gene in $B$. cereus strain 14579. We show that this $T$ box element is functional, responding in a canonical manner to an increased level of uncharged tRNA ${ }^{\text {Lys }}$ but, unusually, also responding to an increased level of uncharged tRNA ${ }^{\text {Asn }}$. We also show that $B$. subtilis strains with $T$ box regulated expression of the endogenous lys $S$ or the heterologous lysk genes are viable.

Conclusions: The T box element controlling lysK (encoding LysRS1) expression in B. cereus strain 14579 is functional, but unusually responds to depletion of charged tRNA ${ }^{\text {Lys }}$ and tRNA ${ }^{\text {Asn }}$. This may have the advantage of making LysRS1 expression responsive to a wider range of nutritional stresses. The viability of $B$. subtilis strains with a single LysRS1 or LysRS2, whose expression is controlled by this T box element, makes the rarity of the occurrence of such control of LysRS expression puzzling.

\section{Background}

The aminoacyl tRNA synthetase (AARS) family of enzymes function to attach amino acids to their cognate tRNAs [1-3]. Each enzyme specifically charges a tRNA with its cognate amino acid in an energy requiring reaction that is executed with very high fidelity. However, despite all AARSs carrying out essentially the same reaction, the AARS family is subdivided into class I and class II enzymes that are structurally distinct and

\footnotetext{
* Correspondence: kdevine@tcd.ie

${ }^{1}$ Smurfit Institute of Genetics, Trinity College Dublin, Dublin 2. Ireland
}

unrelated phylogenetically [for reviews see $[3,4]]$. This division of AARS into class I and class II enzymes is universal with each AARS being a member of one or other enzyme class in all living organisms. The lysyltRNA synthetase (LysRS) is an exception in that both class I (LysRS1) and class II (LysRS2) variants exist [5,6]. LysRS1 enzymes are found in Archaebacteria and in some eubacteria (eg. Borrelia and Treponema species) while LysRS2 enzymes are found in most eubacteria and all eukaryotes. Interestingly some bacteria have both class I LysRS1 and class II LysRS2 enzymes. For example, in Methanosarcina barkeri the class I and class II 
LysRS enzymes function as a complex to charge tRNA ${ }^{\text {Pyl }}$ with the rare pyrolysine amino acid while in $B$. cereus strain 14579 both enzymes can function together to aminoacylate a small tRNA-like molecule (tRNA ${ }^{\text {Other }}$ ) that functions to control expression TrpRS1 [7-9].

Sustaining charged tRNAs at levels adequate for the protein synthetic needs of growth under each environmental and nutritional condition is crucial for cell survival. Achieving this mandates that expression of each AARS be responsive to the cellular level of their charged cognate tRNAs. Therefore the mechanisms controlling AARS expression must be able to distinguish their cognate tRNA from other tRNA species and be able to measure the extent to which the pool of cognate tRNA is charged. Expression of the majority of AARSs in Bacillus subtilis is regulated by the $\mathrm{T}$ box antitermination mechanism [10]. This mechanism was first discovered in studies on the regulation of threonyl- and tyrosyl-tRNA synthetase expression in $B$. subtilis [11-13], for a review see 14. The T box elements are widely distributed, being present in Firmicutes, $\delta$-proteobacteria, Chloroflexi, Deinococcales/Thermales and Actinobacteria, and control expression of genes involved in cellular activities other than tRNA charging such as amino acid biosynthesis, amino acid transport and regulation of amino acid metabolism [15-17].

The T-box regulatory element is usually a 200-300 nucleotide untranslated RNA leader sequence containing a conserved $\mathrm{T}$ box sequence, stem-loop structures and a conditional Rho-independent terminator located upstream of the start codon [11-13]. Two specific interactions between tRNAs and T box leader sequences enable recognition of cognate tRNA species and distinction between charged and uncharged pools of tRNA. The NCCA sequence in the acceptor stem of a nonacylated-tRNA interacts with the UGGN sequence within the $\mathrm{T}$ box sequence ( $\mathrm{N}$ varies according to the identity of the discriminator base of each tRNA) $[13,14,18,19]$. This interaction cannot occur when a tRNA is aminoacylated, thereby distinguishing between charged and uncharged tRNAs. Specificity for cognate tRNAs is achieved by the presence of a specifier codon within a bulge in stem I of the leader sequence that interacts with the anticodon sequence of each tRNA. (eg. See Additional file 1, Figure S5). Thus for $\mathrm{T}$ box control of AARS expression, a high level of an uncharged tRNA (necessitating increased AARS production) causes interaction between that tRNA and its cognate T box element that stabilizes the anti-termination structure of the leader sequence allowing transcription of the AARS gene to proceed. A high level of aminoacylated-tRNAs in contrast cannot interact with the leader sequence allowing formation of the Rho-independent terminator and preventing continued transcription of the gene.
While most eubacteria encode either a class I or a class II LysRS, all sequenced strains of $B$. cereus (except strain AH820) and B. thuringiensis encode a copy of both enzyme types $[8,16,17]$. In Bacillus cereus strain 14579, the LysRS2-encoding lysS gene is positioned at the end of an operon encoding genes involved in folate metabolism, its normal position in most Bacilli while the lysK gene encoding the class I-type LysRS1 is located elsewhere on the chromosome. Shaul et al. (2006) show that this LysRS1 is closely related to the class I LysRS1 of Pyrococcus, suggesting that it has been acquired by $B$. cereus by horizontal transfer [20]. The function of LysRS1 in B. cereus is not clear but it is expressed predominantly in stationary phase and can aminoacylate a novel tRNA species (tRNA ${ }^{\text {Other }}$ ) in concert with the class II LysRS enzyme [8]. Thus it may play a role in surviving nutritional downshift in B. cereus.

Ataide and colleagues reported the presence of a putative $\mathrm{T}$ box regulatory element upstream of the lysK coding sequence in B. cereus strain 14579 [8]. This was the first reported instance of putative control of LysRS expression by a $\mathrm{T}$ box mechanism. Here we investigate control of LysRS expression by a $\mathrm{T}$ box mechanism, confirming that it occurs only very rarely in bacteria. We show that the $\mathrm{T}$ box element of the lysK gene of $B$. cereus strain 14579 is functional and responds to an increased level of uncharged tRNA ${ }^{\text {Lys }}$ in a canonical manner. Interestingly, this $\mathrm{T}$ box element shows some promiscuity in its specificity by responding to a reduced cellular level of asparaginyl-tRNA ${ }^{\text {Asn }}$. We also show that strains of $B$. subtilis, in which expression of the endogenous LysRS2 or the heterologous LysRS1 is controlled by this $\mathrm{T}$ box element, are viable.

\section{Results}

Regulation of lysyl tRNA synthetase expression by a T-box antitermination mechanism occurs rarely

A search of the upstream region of AARS-encoding genes in 891 completely sequenced bacterial genomes identified $976 \mathrm{~T}$ box elements. Significant variation in the frequency with which individual AARS are regulated by a $\mathrm{T}$ box mechanism was observed in this cohort, consistent with previous reports $[16,17]$. Control of LysRS expression by $\mathrm{T}$ box elements occurs very rarely, being documented in only 4 bacterial species: all sequenced B. cereus strains (except AH820); in B. thuringiensis strains Konkukian and Al Hakam; in Clostridium beijerinckii and in Symbiobacterium thermophilum $[8,16,17]$. These cases display several interesting features (Table 1): (i) all bacterial species with T-box regulated LysRS expression have a second LysRS that is not T-box regulated; (ii) the phylogenetically related B. cereus and B. thuringiensis species each have a class II LysRS2 and a T-box regulated class I LysRS1 - these T box regulatory 
Table 1 Occurrence of $\mathrm{T}$ box regulated lysyl-tRNA synthetase genes

\begin{tabular}{|c|c|c|c|c|}
\hline Bacterium & Gene & $\begin{array}{l}\text { Gene } \\
\text { identifier }\end{array}$ & Class & $\begin{array}{l}\mathrm{T} \text { box } \\
\text { regulated }\end{array}$ \\
\hline \multirow[t]{2}{*}{ B. cereus strains§ } & lyss & & $\|$ & No \\
\hline & lysk & & 1 & Yes \\
\hline \multirow[t]{2}{*}{ B. thuringiensis Konkukian } & lyss & BT9727_0072 & $\|$ & No \\
\hline & lysk & BT9727_2375 & I & Yes \\
\hline \multirow[t]{2}{*}{ B. thuringiensis Al Hakam } & lyss & BALH_0075 & $\|$ & No \\
\hline & lysk & BALH_2333 & 1 & Yes \\
\hline \multirow[t]{2}{*}{ Clostridium beijerinckii } & lyss1 & Cbei_0105 & $\|$ & No \\
\hline & lyss2 & Cbei_3591 & $\|$ & Yes \\
\hline \multirow{2}{*}{$\begin{array}{l}\text { Symbiobacterium } \\
\text { thermophilum }\end{array}$} & lyss & STH525 & $\|$ & Yes \\
\hline & lysk & STH2O8 & 1 & No \\
\hline
\end{tabular}

elements show very high sequence conservation ( $92 \%$ identity, Additional file 1, Figures S1, S5); (iii) conversely in S. thermophilum, the class II LysRS2 (STH525) is regulated by a $T$ box element with little similarity to that found in the Bacillus species (Additional file 1, Figures S3, S7) while the class I LysRS1 (STH208) is not T box regulated and (iv) C. beijerincki has two classII LysRS (Cbei_3591 and Cbei_0105), one of which (Cbei_3591) is regulated by a $\mathrm{T}$ box element that displays clear sequence similarity ( $\sim 50 \%$ identity) to the T box found in the Bacillus species (see Additional file 1, Figures S2, S6), but little similarity to the $\mathrm{T}$ box element of $S$. thermophilum (Additional file 1, Figure S4). Thus $\mathrm{T}$ box regulated LysRS expression is very rare and is invariably accompanied by a second non-T-box regulated (either class I or class II) LysRS. Two separate T box elements were identified - one controlling expression of a class II LysRS2 in $S$. thermophilum and the second controlling expression of a class I LysRS1 in B. cereus and B. thuringiensis but a class II LysRS2 in C. beijerinckii

\section{The T-box element controlling expression of lysK in $B$. cereus strain 14579 is functional}

The T-box element in the B. cereus and B. thuringiensis strains has a canonical structure [8], is highly conserved and controls expression of a class I LysRS (encoded by the lysK gene) of Pyrococcal origin [20]. Interestingly, the lysK gene is expressed predominantly during stationary phase in B. cereus strain 14579, whereas the class II LysRS is expressed during exponential growth of this bacterium [8]. To ascertain whether this T-box element is functional, expression of a $\mathrm{P}_{l y s K(\mathrm{~T} \text { box })}$ lac $Z$ transcriptional fusion (present in single copy at the amyE locus of the B. subtilis chromosome) was established under conditions of lysine starvation (strain NF33 is a lysine auxotroph) and LysRS2 depletion (strain BCJ367 has the endogenous lysS gene under the control of the IPTG-inducible $\mathrm{P}_{\text {spac }}$ promoter).
The results are shown in Figure 1. When strain NF33 is grown in lysine replete medium, only a low level of $\mathrm{P}_{l y s K(\mathrm{~T}}$ box) lac $Z$ expression ( 10 units of $\beta$-galactosidase activity) is observed (Figure 1A, squares). However growth in a lysine depleted medium (growth cessation occurs at $\sim \mathrm{OD}_{600} 1$ due to lysine deficiency) results in a high level of $\mathrm{P}_{l y s K(\mathrm{~T} \text { box })}$ lac $Z$ expression, with accumulation of $\sim 1200$ units of $\beta$ galactosidase activity. Importantly $\mathrm{P}_{\text {lys } K(\mathrm{~T} \text { box })}$ lac $Z$ induction is coincident with the point of growth cessation due to lysine deficiency (Figure 1A). To confirm that increased $\mathrm{P}_{l y s K(\mathrm{~T} \text { box })}$ lac $Z$ expression is associated with increased levels of uncharged tRNA ${ }^{\text {Lys }}$, strain BCJ367 $\left(\mathrm{P}_{\text {spac }}\right.$ lys $\mathrm{P}_{\text {lysK }}$ (T box) lacZ) was grown in the presence of $1 \mathrm{mM}$ IPTG, $250 \mu \mathrm{M}$ IPTG and $100 \mu \mathrm{M}$ IPTG. Growth of the cultures containing $1 \mathrm{mM}$ and $250 \mu \mathrm{M}$ IPTG was similar to that of wild-type strain 168 while growth of the cultures with $100 \mu \mathrm{M}$ IPTG was reduced, presumably due to a decreased level of charged lysyl-tRNA ${ }^{\text {Lys }}$ (Figure 1B). Expression of $\mathrm{P}_{\text {lysK (T box) }}$ lac $Z$ is low ( 10 units $\beta$-galactosidase activity) in cultures containing $1 \mathrm{mM}$ IPTG. $\mathrm{P}_{l y s K(\mathrm{~T} \text { box })}$ lac $Z$ expression is initially low in cultures containing $250 \mu \mathrm{M}$ IPTG but gradually increases with accumulation of $\sim 200$ units of $\beta$-galactosidase activity at the onset of stationary phase. However in cultures with $100 \mu \mathrm{M}$ IPTG, $\mathrm{P}_{\text {lysK(T box })}$ lac $Z$ expression increases throughout exponential growth with accumulation of more than 800 units of $\beta$-galactosidase during this period (Figure 1B). To confirm that this increased $\mathrm{P}_{\text {lys } K(\mathrm{~T} \text { box })}$ lac $Z$ expression is due to increased levels of uncharged tRNA ${ }^{\text {Lys }}$ caused by LysRS2 depletion, a culture was grown for 150 minutes in the presence of $100 \mu \mathrm{M}$ IPTG at which point, the IPTG concentration was increased to $1 \mathrm{mM}$ (Figure 1C). Results showed accumulation of $\sim 1200$ units of $\beta$-galactosidase activity at $150 \mathrm{~min}$ utes but this level decreased subsequent to IPTG addition and continued to decrease for the remaining period of exponential growth (Figure 1C). It is noteworthy that the growth rate also increased upon IPTG addition (Figure 1C). As a control we established that $\mathrm{P}_{l y s K(\mathrm{~T} \text { box })}$ lac $Z$ expression is not induced by cellular depletion of phenylalanine showing that its induction shows the expected specificity (data not shown). These data show that the $\mathrm{T}$ box regulatory element found in the control region of the class I lys $K$ gene of $B$. cereus strain 14579 is functional and responds to increased levels of uncharged tRNA ${ }^{\text {Lys }}$ in a canonical manner.

\section{A B. subtilis strain expressing the $B$. cereus class I LysK under $\mathrm{T}$ box regulatory control is viable}

The rarity of the $\mathrm{T}$ box control of LysRS expression, and where found, occurs only in conjunction with a second cellular LysRS, prompted us to ask whether $\mathrm{T}$ box control of LysRS expression is compatible with viability. To address this question, B. subtilis strain NF54 (amyE:: $\mathrm{P}_{l y s K(\mathrm{~T} \text { box) }}$ lysK JlysS) was constructed in which 

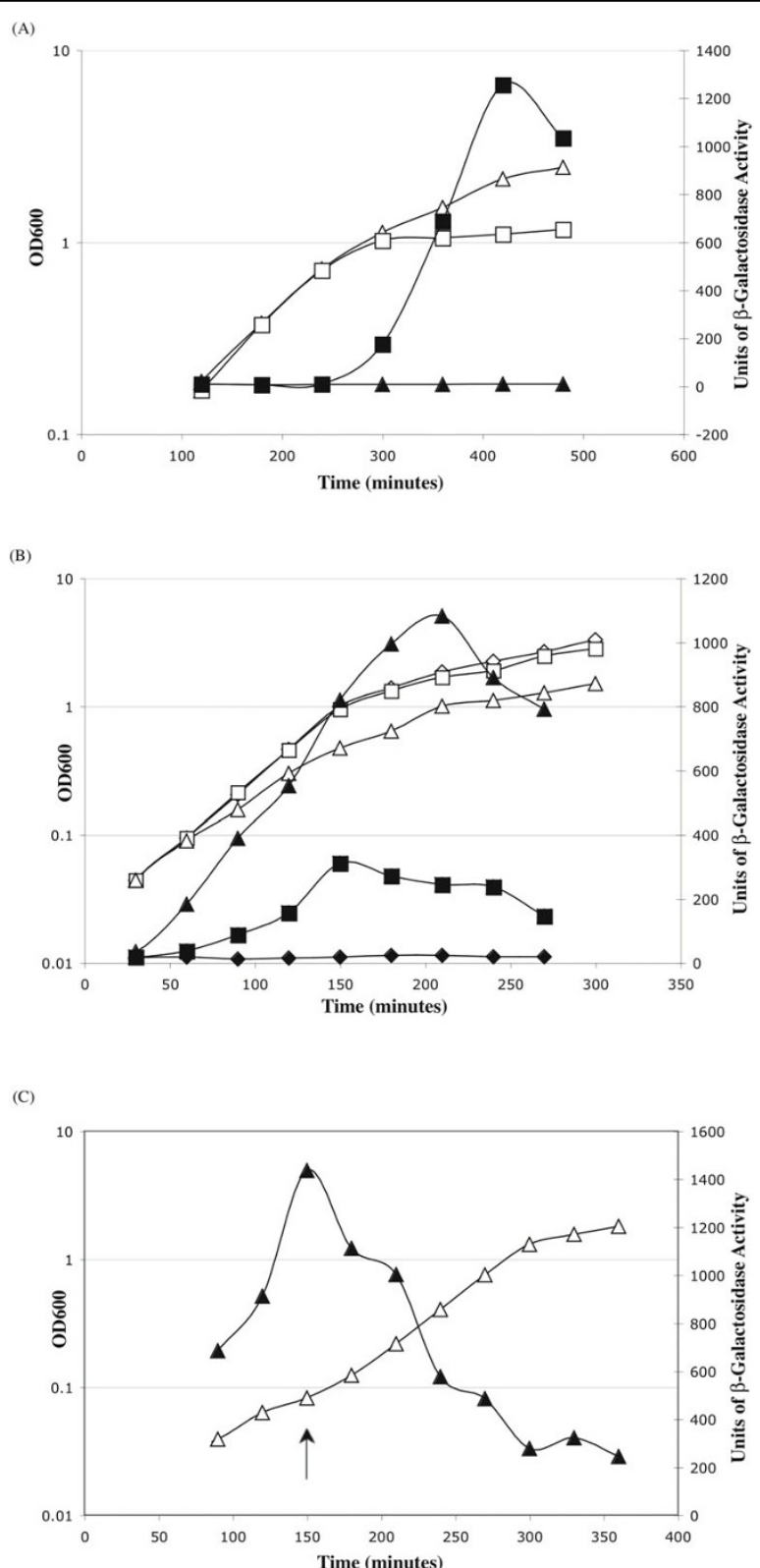

Figure 1 Response of the $B$. cereus lysK T-box regulatory element to reduced tRNA ${ }^{\text {Lys }}$ charging. Growth is represented by open symbols and $\beta$-galactosidase activity by closed symbols. Representative expression profiles are presented. Growth is represented by open symbols and $\beta$ galactosidase activity by closed symbols. (A) Growth and $\beta$-galactosidase accumulation in strain NF33 ( $\mathrm{P}_{\text {lysk }}$ (T box) lacZ) in minimal media. Strain NF33 was grown in minimal medium containing $100 \mu \mathrm{g} / \mathrm{ml}$ lysine (triangles) and $20 \mu \mathrm{g} / \mathrm{ml}$ lysine (squares). (B) Growth and $\beta$-galactosidase accumulation in strain BCJ367 ( $\mathrm{P}_{\text {lysk Tbox }}$ lacZ $\mathrm{P}_{\text {spac }}$ lysS pMap65) in LB containing varying IPTG concentrations: 1 mM IPTG (diamonds); $250 \mu$ M IPTG (squares) and $100 \mu \mathrm{M}$ IPTG (triangles). (C) Growth and $\beta$-galactosidase activity of strain BCJ367 in LB containing 100 $\mu$ M IPTG. The IPTG concentration was increased to $1 \mathrm{mM}$ at 150 minutes, indicated by the arrow.

expression of the B. cereus lysK gene is under the control of its natural promoter and $\mathrm{T}$ box regulatory element in single copy at the amyE locus and the endogenous lys $S$ gene is partially deleted (373 amino acids of LysRS deleted leaving only the C-terminal 126 amino acids) by a double cross-over event. It is important to note that in strain NF54 the $\mathrm{P}_{l y s K(\mathrm{~T} \text { box })} l y s K$ cassette is flanked by transcriptional terminators, ensuring that lysK expression is solely dependent on the $\mathrm{P}_{\text {lys } K}$ ( $\mathrm{T}$ box) promoter. This strain was successfully constructed and verified by PCR and Southern blot analysis and by sequencing of selected regions (data not shown). This confirms that in B. subtilis $\mathrm{T}$ box mediated control of LysRS1 expression is compatible with viability. To 
establish whether NF54 has a phenotype, growth profiles were established in rich (LB) and minimal media and compared with wild-type B. subtilis strain 168 . Results show an increase in the generation time of strain NF54 during growth in LB medium: NF54 has a doubling time of $\sim 31$ minutes while that of wild-type strain 168 is $\sim 22$ minutes under these conditions. However strain NF54 does not grow in minimal medium whereas wild-type strain 168 has a generation time of 76 minutes in this medium. To establish whether this growth phenotype was due to reduced tRNA ${ }^{\text {Lys }}$ charging, the $\mathrm{P}_{\text {lys } K \text { ( } \mathrm{T} \text { box })}$ lac $Z$ was introduced into strain NF54 generating strain NF206. Reduced charging of tRNA ${ }^{\text {Lys }}$ in strain NF206 will result in increased $\beta$-galactosidase accumulation when compared with strain BCJ363 that has the $\mathrm{P}_{l y s K(\mathrm{~T}}$ box) lac $Z$ contruct in an otherwise wild-type background (ie. with the endogenous class II lysS). Results show that 250-300 units of $\beta$-galactosidase accumulate during exponential growth of strain NF206, an $\sim 20$-fold increase over that observed in the control strain BCJ363. We conclude $\mathrm{T}$ box control of LysR1 expression is compatible with viability of $B$. subtilis. However such strains have a reduced growth rate in rich medium and cannot be propagated in minimal medium probably due to reduced tRNA ${ }^{\text {Lys }}$ charging.

\section{A B. subtilis strain with expression of the endogenous class II lysS under the control of the $T$ box regulatory element is viable and indistinguishable from wild-type in terms of growth and tRNA ${ }^{\text {Lys }}$ charging}

While $\mathrm{T}$ box control of LysRS1 expression supports growth of B. subtilis, the level of charged tRNA ${ }^{\text {Lys }}$ is reduced and there is a growth phenotype. However it is unclear whether this phenotype is caused by $\mathrm{T}$ box regulation of LysRS expression or is due to the B. cereus derived class I LysRS1 enzyme that is reported to be less efficient catalytically than its class II counterpart [21]. To distinguish between these possibilities and to further address the issue of $\mathrm{T}$ box regulation of LysRS, we constructed strain NF113 (lysS:: $\mathrm{P}_{l y s K(\mathrm{~T} \text { box })}$ lysS) that placed expression of the endogenous $B$. subtilis lys $S$ gene under the control of the lys $K$ promoter and $\mathrm{T}$ box element from B. cereus strain 14579. It is important to note that in strain NF113 the $\mathrm{P}_{l y s K(\mathrm{~T} \text { box })}$ lys $S$ cassette is flanked by transcriptional terminators ensuring that lys $S$ expression is solely dependent on the $\mathrm{P}_{\text {lysK(T box) }}$ promoter. Strain NF113 was successfully constructed and the relevant chromosomal regions verified by PCR and Southern blotting (data not shown) confirming that $\mathrm{T}$ box regulation of LysRS2 expression supports growth of B. subtilis. Importantly growth of strain NF113 in rich (LB) and minimal media (Spizizen salts) was indistinguishable from wild-type strain 168 (data not shown). The level of charged tRNA ${ }^{\text {Lys }}$ was assessed in strain
NF113 by introducing the $\mathrm{P}_{\text {lys } K \text { (T box })}$ lacZ transcriptional fusion to generate strain NF205. Approximately 10 units of $\beta$-galactosidase accumulated during exponential growth of strain NF205 similar to control strain BCJ363 (data not shown). We conclude that T box control of lysS expression is compatible with growth of B. subtilis. It is likely that the growth and tRNA ${ }^{\text {Lys }}$ charging deficiency of strains NF54 and NF206 (containing $\mathrm{T}$ box regulated LysRS1) is caused by decreased efficiency of tRNA ${ }^{\text {Lys }}$ charging by LysRS1 rather than by $\mathrm{T}$ box control of its expression.

\section{The T box element associated with the $B$. cereus class I} LysRS1 can be partially induced by asparagine starvation The results presented show that while $\mathrm{T}$ box regulation of LysRS expression occurs very rarely and invariably in conjunction with a non- $\mathrm{T}$ box regulated paralogue, control of expression of the main LysRS by a $\mathrm{T}$ box mechanism is compatible with viability. This prompted us to question why $\mathrm{T}$ box regulation of LysRS expression does not occur more frequently. We noted that expression of neither LysRS nor AsnRS is regulated by a $\mathrm{T}$ box mechanism in Bacilli and that these two amino acids are encoded in a mixed codon box (Figure 2A). We therefore hypothesized that the $\mathrm{T}$ box element that controls expression of the class I LysRS1 of B. cereus may be inducible both by uncharged tRNA ${ }^{\text {Lys }}$ and tRNA $^{\text {Asn }}$. A prediction of this hypothesis is that cellular depletion of charged tRNA ${ }^{\text {Asn }}$ may induce expression of $\mathrm{P}_{\text {lysK(T box })}$ lacZ. To test this hypothesis, strain NF60 $\left(\mathrm{P}_{\text {spac }}\right.$ asnS $\mathrm{P}_{\text {lysK(T box })}$ lacZ) was constructed containing the asnS gene under the control of the inducible $\mathrm{P}_{\text {spac }}$ promoter (there is no B. subtilis asparagine auxotroph) and the $\mathrm{P}_{\text {lys } K \text { (T box }}$ lac $Z$ to monitor induction. The growth profiles of NF60 cultures containing $1 \mathrm{mM}$ and $250 \mu \mathrm{M}$ IPTG were identical, but $\beta$-glactosidase accumulation differed significantly under these two conditions. Approximately 30 units of $\beta$-galactosidase accumulated during exponential growth of the culture containing $1 \mathrm{mM}$ IPTG while more than 350 units of $\beta$-galactosidase accumulated during exponential growth of the culture containing $250 \mu \mathrm{M}$ IPTG (data not shown). To exclude the possibility that depleting cellular levels of AsnRS leads to a concomitant increase in the uncharged tRNA ${ }^{\text {Lys }}$ level (and hence increased $\mathrm{P}_{l y s K(\mathrm{~T}}$ box) lac $Z$ expression) we established the highest IPTG concentration at which some induction of $\mathrm{P}_{l y s K(T \text { box })}$ lac $Z$ occurred but at which growth of the culture was unaffected. The growth profiles of NF60 cultures containing $1 \mathrm{mM}$ IPTG and $600 \mu \mathrm{M}$ IPTG are identical (Figure 2B). However $\sim 20-40$ units of $\beta$-galactosidase accumulate during exponential growth of the culture containing $1 \mathrm{mM}$ IPTG while more than 80 units of $\beta$-galactosidase accumulate during exponential growth 
(A)

\section{AAT Asn \\ AAC Asn \\ AAA Lys \\ AAG Lys}

(B)

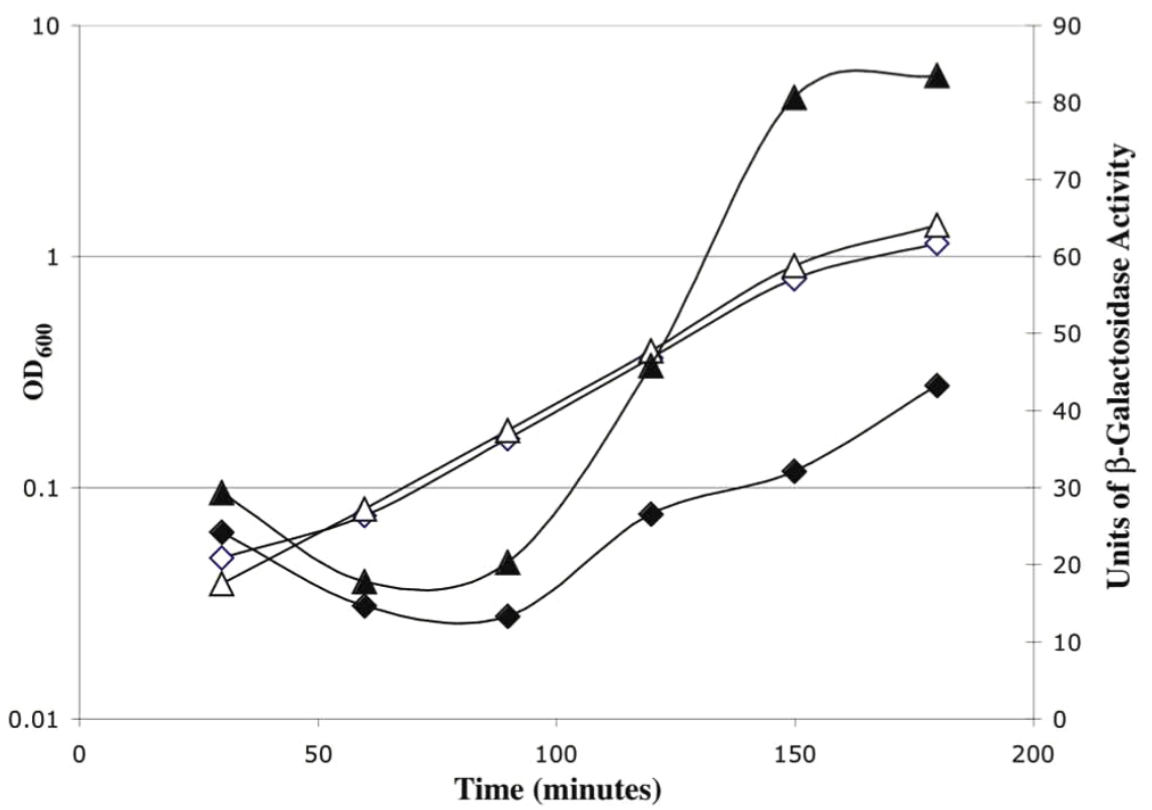

(C)

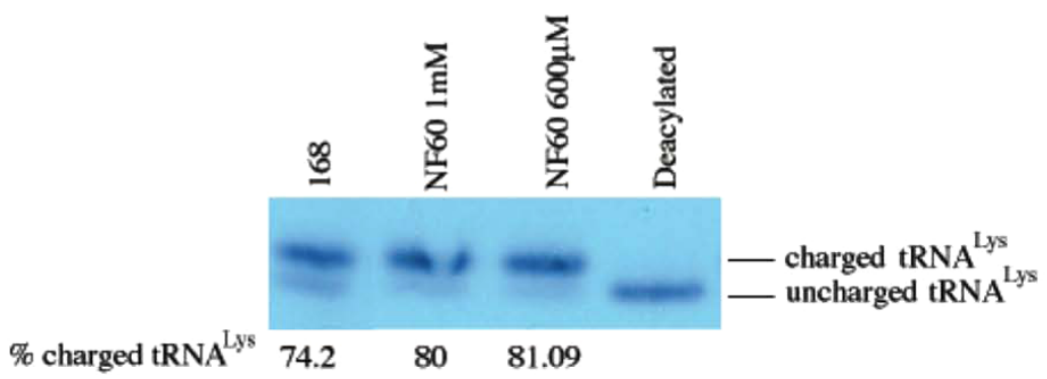

Figure 2 Response of the $B$. cereus lysK T-box regulatory element to reduced levels of charged tRNA ${ }^{A s n}$. A) The mixed codon box for lysine and asparagine. (B) Growth (open symbols) and $\beta$-galactosidase activity (closed symbols) of NF60 ( $P_{\text {spac }}$ asnS P $P_{\text {lysk Tbox }}$ lacZ pMAP65) in LB containing $1 \mathrm{mM}$ (diamonds) and $600 \mu \mathrm{M}$ (triangles) IPTG. (C) Northern analysis of tRNA ${ }^{\text {Lys }}$ charging in wild-type B. subtilis strain 168 and strain NF60 growing in LB media with the indicated IPTG concentrations. The percentage of charged tRNA ${ }^{\text {Lys }}$ is indicated beneath each lane. The profiles presented are representative.

of the culture containing $600 \mu \mathrm{M}$ IPTG. Importantly the kinetics of $\mathrm{P}_{\text {lys } K \text { ( } \mathrm{T} \text { box) }}$ lac $Z$ expression differed in the two cultures: an increase in $\beta$-galactosidase accumulation is evident in the $600 \mu \mathrm{M}$ culture that is not seen in the $1 \mathrm{mM}$ IPTG culture. To verify that this induction is not due to an increased level of uncharged tRNA ${ }^{\text {Lys }}$, the cellular level of lysyl-tRNA ${ }^{\text {Lys }}$ was measured in wild-type strain 168 and in cultures of NF60 grown in $1 \mathrm{mM}$ and $600 \mu \mathrm{M}$ IPTG (Figure 2C). It is clear that the level of lysyl-tRNA ${ }^{\text {Lys }}$ is approximately the same $(\sim 80 \%)$ in both 
IPTG-containing cultures of NF60, a level that is higher than that observed $(\sim 74 \%)$ in cultures of wild-type B. subtilis strain 168 grown in the same medium (without IPTG). As an additional control, we measured $\mathrm{P}_{\text {lys }}$ ( $\mathrm{T}$ box) lac $Z$ expression and charged tRNA ${ }^{\text {Lys }}$ levels in cultures of strain $\mathrm{BCJ} 367$ ( $\mathrm{P}_{\text {spac }}$ lys $S \mathrm{P}_{\text {lys } K(\mathrm{~T} \text { box }}$ lac $Z$ ) growing in $1 \mathrm{mM}$ and $600 \mu \mathrm{M}$ IPTG. Approximately 20-30 units of $\beta$-galactosidase accumulated in both cultures and importantly the level of charged tRNA ${ }^{\text {Lys }}$ in both cultures was $\sim 83 \%$ (data not shown).

We then sought to establish (i) if depletion of the cellular level of a charged tRNA leads to a general reduction in level of other charged tRNAs and (ii) if some level of cross-induction exists among $\mathrm{T}$ box elements controlling expression of AARS that charge the constituent tRNAs of mixed codon boxes in B. subtilis. To address both issues, transcriptional fusions of the promoter and $\mathrm{T}$ box element of the pheS, ileS and trpS AARS genes of $B$. subtilis with the lacZ reporter gene were constructed. Each fusion was introduced into strains auxotrophic for their cognate amino acids and into strains auxotrophic for the non-cognate amino acid in the mixed codon box. In each case, depletion for the cognate amino acid resulted in immediate induction of $\beta$-galactosidase expression while depletion for the noncognate amino acid did not induce $\beta$-galactosidase expression to a significant level in any case (data not shown). These data show that depletion for an individual amino acid does not lead to a general increase in the level of uncharged tRNAs of other amino acids and that promiscuous cross-induction of $\mathrm{T}$ box controlled promoters by depletion of the non-cognate amino acid of a mixed codon box does not occur in B. subtilis.

We conclude that the $\mathrm{T}$ box element controlling expression of lys $K$ encoding the class I LysRS1 of B. cereus strain 14579 displays some promiscuity of induction, being capable of responding to an increased level of uncharged tRNA $^{\text {Asn }}$ in addition to uncharged tRNA ${ }^{\text {Lys }}$. However such promiscuous cross-induction is not a general feature of $\mathrm{T}$ box elements in B. subtilis.

\section{Discussion}

\section{$\mathrm{T}$ box regulation of LysRS expression occurs rarely and in} exceptional circumstances

The $\mathrm{T}$ box mechanism is widely employed to regulate AARS expression in a manner that is responsive to the level of uncharged cognate tRNA in the cell. Of $976 \mathrm{~T}$ box elements associated with regulation of AARS expression in 891 completely sequenced bacterial genomes identified in our analysis, potential $\mathrm{T}$ box control of LysRS expression was identified in only 4 bacterial species: $\mathrm{T}$ box elements were identified in all sequenced strains of B. cereus (except AH820) and B. thuringiensis, in association with a class I LysRS1 of Pyrococcal origin
[8]; a $\mathrm{T}$ box element was identified in C. beijerinckii associated with a class II LysRS2 [17] and a T box element was identified in S. thermophilum, associated with a class I LysRS1 [16]. The T box elements in the Bacillus and Clostridium species are homologous: the $\mathrm{T}$ box elements of the Bacillus strains are $~ 92 \%$ identical while $\sim 50 \%$ identity exists between the $\mathrm{T}$ box elements of the Bacillus and Clostridium species (see Additional file 1, Figure S1). However the T box element of S. thermophilum appears unrelated to the other $\mathrm{T}$ box elements (see Additional file 1, Figure S3). This is especially interesting since despite its high $\mathrm{G}+\mathrm{C}(68.7 \%)$ content, S. thermophilum proteins are more similar to those of the low $\mathrm{G}+\mathrm{C}$ Firmicutes such as Bacilli and Clostridia than to the high $\mathrm{G}+\mathrm{C}$ Actinobacteria. In view of this, it is also interesting that among the homologous $\mathrm{T}$ box elements, those in the Bacilli are associated with a class I LysRS while the $\mathrm{T}$ box element in C. beijerinckii is associated with a class II LysRS. Thus $\mathrm{T}$ box regulation of LysRS expression appears to have evolved on two separate occasions, and one $\mathrm{T}$ box element has been conjoined with two different LysRS-encoding genes.

There are several interesting features about this cohort of $\mathrm{T}$ box regulated LysRS: (i) all bacterial species with a $\mathrm{T}$ box regulated LysRS have a second LysRS that is not $\mathrm{T}$ box regulated; (ii) the four $\mathrm{T}$ box elements in the phylogenetically related $B$. cereus and $B$. thuringiensis species are associated with a class I LysRS1 and display $\sim 92 \%$ identity; (iii) the class I LysRS1 of B. cereus and B. thuringiensis is most closely related to LysRS1 from Pyrococcal species suggesting that a common ancestor of $B$. cereus/thuringiensis acquired it by a lateral gene transfer event [20]; (iv) the T box regulated LysRS1 in B. cereus strain 14579 is expressed predominantly in stationary phase [8] and (v) T box elements do not occur in Archaebacteria. The likely Pyrococcal origin of B. cereus LysRS1 and the absence of $\mathrm{T}$ box elements in Archaebacteria presents an interesting question as to how the regulatory sequence and structural gene were conjoined in this case. Perhaps tRNA ${ }^{\text {Lys }}$-responsive T box elements were more common in the ancestor of Firmicutes (supported by a similar $\mathrm{T}$ box element being associated with a class II LysRS2 in C. beijerinckii) and were selectively lost as controlling elements of the principal cellular LysRS, but were retained for control of ancillary LysRS enzyme expression. A second interesting possibility, especially in view of the fact that it can be induced by tRNA ${ }^{\mathrm{Asn}}$, is that the $\mathrm{T}$ box element associated with lysK of B. cereus may have evolved from an element with a specificity determinant similar in sequence to that of lysine. These observations suggest that $\mathrm{T}$ box regulation may be unsuited for controlling expression of the housekeeping LysRS in bacteria and perhaps is only tolerated in additional copies of LysRS 
that play an ancillary role such as adaptation to stationary phase conditions as observed in B. cereus. Determining whether the other $\mathrm{T}$ box regulated lys $S$ genes play an ancillary role requires further investigation. Notably, $\mathrm{T}$ box regulation of housekeeping aminoacyl tRNA synthetases is widespread, suggesting that it is some aspect of lysine metabolism that makes $\mathrm{T}$ box control of LysRS expression unsuitable as a regulatory mechanism.

\section{The LysRS1 T box element from $B$. cereus is functional and $B$. subtilis strains with T box control of LysRS1 and LysR2 expression are viable}

The unknown provenance and functionality of the $\mathrm{T}$ box element, despite the reported theoretical capability to form canonical $\mathrm{T}$ box element structures [8] prompted us to verify that it was functional and to ask whether strains of $B$. subtilis expressing a single copy of LysRS1 or LysRS2 controlled by this T box element are viable. We chose to conduct this study in B. subtilis because of the paucity of relevant auxotrophic $B$. cereus strains and other difficulties with antibiotic resistance and transformability. However we consider B. subtilis to be a valid model system in which to conduct this study. Our results show that the $\mathrm{T}$ box element is functional and can be induced up to 120 -fold in response to lysineor LysRS-depletion but not by depletion of non-cognate amino acids. Also strains of $B$. subtilis with expression of the endogenous LysRS2 controlled by this T box element are viable, and could not be distinguished from $B$. subtilis wild-type strain 168 during growth in rich or minimal medium. While a strain of $B$. subtilis expressing LysRS1 controlled by the T box element from $B$. cereus strain 14579 is also viable, it displays a growth defect when grown in rich medium and cannot be propagated in minimal medium. However it is likely that these phenotypes result from the reduced catalytic activity of class I LysRS enzyme rather than from control of expression by the $\mathrm{T}$ box element. These results show there is no a priori reason precluding control of LysRS expression by a tRNA ${ }^{\text {Lys }}$-responsive T box element. It emphasizes the puzzling rarity of $\mathrm{T}$ box regulated LysRS expression and the restriction of its occurrence in B. cereus strain 14579 to controlling expression of a LysRS1 enzyme that plays an ancillary role in adapting cells to adverse conditions.

\section{The T box element controlling expression of LysRS1 in $B$. cereus strain 14579 can be induced by an increased level of uncharged tRNA ${ }^{\text {Asn }}$}

The unusual occurrence of tRNA ${ }^{\text {Lys }}$-responsive $T$ box elements and the experimentally demonstrated viability of B. subtilis strains with $\mathrm{T}$ box regulated LysRS expression prompted us to investigate why $\mathrm{T}$ box regulation of LysRS expression is rare. We noted a tendency in
B. subtilis for non-T box regulated AARS (ArgRS, AsnRS, GltRS, LysRS, MetRS, and ProRS) to charge tRNAs with amino acids encoded in mixed codon boxes (ProRS being an exception, not being encoded by a mixed codon box). This observation, together with its possible origin being a $\mathrm{T}$ box element that is responsive to a different tRNA, prompted us to investigate whether the $\mathrm{T}$ box element controlling LysRS1 expression in $B$. cereus might also be induced by depletion of asparaginyl-tRNA ${ }^{\text {Asn }}$. Our results show that cellular depletion of AsnRS in B. subtilis results in induction of the $\mathrm{P}_{\text {lys } K(\mathrm{~T} \text { box })}$ lacZ. We show that this induction is not caused by concomitant depletion of lysyl-tRNA ${ }^{\text {Lys }}$ since induction occurs when cellular levels of charged tRNA ${ }^{\text {Lys }}$ are high (Figure 2). Importantly, there is no direct link in the biosynthetic pathways of lysine and asparagine. Also, expression of $\mathrm{P}_{\text {lys } K \text { ( } \mathrm{T} \text { box) }}$ lac $Z$ does not occur when cells are depleted for phenylalanine, showing that induction displays the expected specificity for lysine starvation. These data show that the $\mathrm{T}$ box element controlling expression of LysRS1 of B. cereus can be induced by an increased level of uncharged tRNA ${ }^{\text {Lys }}$ and tRNA ${ }^{\text {Asn }}$. However such promiscuity of induction is restricted to this lysK-associated $\mathrm{T}$ box element since $\mathrm{T}$ box element control of expression of AARSs within mixed codon boxes is frequently found [17] and induction of the T box-controlled pheS, ileS and trpS genes was not observed in response to starvation for the non-cognate amino acid of the mixed codon box. The induction promiscuity of the $B$. cereus LysRS1-associated T box element might derive from its having evolved from a $\mathrm{T}$ box element that responded to a different tRNA. Such promiscuity may be tolerated since LysRS1 in B. cereus appears to have an ancillary role during stationary phase, or it may even be advantageous in that it makes LysRS1 expression responsive to a broader range of adverse nutritional conditions.

\section{Conclusions}

The $\mathrm{T}$ box regulatory element makes expression of AARS responsive to the uncharged level of their cognate tRNA and is widely used among bacteria. However significant variability exists in the frequency with which expression of individual AARSs is controlled by this mechanism [15-17], this study. It is largely unknown why $\mathrm{T}$ box regulation of LysRS expression is found in only 4 bacterial species (B. cereus, B. thuringiensis, $S$. thermophilum and C. beijerinckii) while more than 140 instances of $\mathrm{T}$ box control of IleRS expression are documented. Moreover these four bacterial species with a $\mathrm{T}$ box regulated LysRS all have a second non- $\mathrm{T}$ box regulated LysRS. We report that two tRNA ${ }^{\mathrm{Lys}}$-responsive $\mathrm{T}$ box elements exist: the first is found in the Bacillus and Clostridium species controlling expression of a class I LysRS1 in Bacillus but a class II LysRS2 in 
Clostridium; the second in S. thermophilum displays little homology to the first $\mathrm{T}$ box element and controls expression of a class II LysRS2. We established that the $\mathrm{T}$ box element associated with lysK expression in $B$. cereus strain 14579 is functional, but unusually responds to an increased level of uncharged tRNA ${ }^{\text {Lys }}$ and tRNA ${ }^{\text {Asn }}$. Since LysRS1 is expressed mainly in stationary phase, this unusual induction profile may make its expression responsive to a wider range of nutritional signals. We also demonstrated that $B$. subtilis cells, in which expression of the endogenous lysS is controlled by the lysK $\mathrm{T}$ box element from $B$. cereus, are viable and are indistinguishable from wild-type $B$. subtilis strain 168 in terms of growth and tRNA ${ }^{\text {Lys }}$ charging. Thus there appears to be no a priori reason why expression of the main cellular LysRS is not regulated by a $\mathrm{T}$ box element in B. subtilis (in fact expression of a majority of the AARS are T box regulated in B. subtilis), making the rarity of $\mathrm{T}$ box control of LysRS expression among bacteria even more puzzling.

\section{Methods}

\section{Bacterial strains, media and growth conditions}

Bacterial strains used in this study are listed in Table 2. Cells were grown routinely at $37^{\circ} \mathrm{C}$ in LB media, Spizizen's minimal media [22] or Basal Limitation media [23]. All cloning in E. coli was carried out in strains TG1 or TP611 [24,25]. Transformation of B. subtilis and E. coli was performed as described $[26,27]$. Antibiotics were used at the following concentrations: ampicillin, $100 \mu \mathrm{g} / \mathrm{ml}$; spectinomycin, $100 \mu \mathrm{g} / \mathrm{ml}$; chloramphenicol, $3 \mu \mathrm{g} / \mathrm{ml}$; erythromycin, $2 \mu \mathrm{g} / \mathrm{ml}$; phleomycin, $1.5 \mu \mathrm{g} / \mathrm{ml}$ and kanamycin, $10 \mu \mathrm{g} / \mathrm{ml}$. IPTG was added to cultures as indicated in the text.

\section{General molecular biology methods}

Standard DNA manipulations and cloning procedures were carried out as described [26]. Chromosomal DNA was isolated from B. subtilis and B. cereus using the chromosomal DNA purification kit from Edge Biosystems (Gaithersburg, MD) according to the manufacturerer's protocol. Plasmid DNA was isolated by a modified boiling lysis method [26] and further purified using the Concert Rapid PCR Purification System (Invitrogen, Carlsbad, CA), or the Genelute Plasmid miniprep kit (Sigma Aldrich, St Louis, MO, USA) according to the manufacturer's instructions. PCR amplification was performed using Taq polymerase (Invitrogen, Carlsbad, CA) or high fidelity KOD polymerase (CalbiochemNovabiochem Corp. USA). Sequencing was carried out by MWG Biotech-Germany (Ebersburg, Germany) and GATC Biotech (Konstanz, Germany). Oligonucleotides used in this study (listed in Table 3) were purchased from MWG Biotech-Germany (Ebersburg, Germany) or
Sigma-Aldrich (St. Louis, MO, USA). For Southern blot analysis DNA was transferred to Biodyne membranes (Pall Gelman, Ann Arbor, MI, USA) by vacuum blotting and crosslinked by UV exposure $(150 \mathrm{~mJ})$. Dig labeled probes (Roche, East Sussex, UK) were prepared as per manufacturer's protocol and hybridized to the filter using high concentration SDS buffers. Filter washes and probe detection were carried out using the Dig detection kit (Roche, East Sussex, UK).

\section{Strain construction}

To construct strain NF33, a 400 bp DNA fragment from the region upstream of $B$. cereus lys $K$ was amplified by PCR using primers NF36F and NF36R, cut with EcoRI and $B a m \mathrm{HI}$, and ligated into similarly restricted pDG268 [28] to produce the plasmid pBCJ307. pBCJ307 was inserted into the amyE locus of the $B$. subtilis lysine auxotroph strain $1 \mathrm{~A} 765$ by double crossover to produce strain NF33.

In order to analyze the effect of a reduction of the cellular level of charged tRNA ${ }^{\text {Lys }}$ on expression of a $\mathrm{P}_{l y s K(\mathrm{~T}}$ box) lac $Z$ fusion, strain BCJ367 was constructed. Plasmid pBCJ307 was integrated into the B. subtilis chromosome by a double crossover event at the amyE locus to produce strain BCJ363. To place the endogenous lysS gene of B. subtilis under IPTG inducible control, plasmid pMUTIN4 [29] was digested with SalI and BsiWI and eluted from an agarose gel to remove the $2 \mathrm{~kb} l a c Z$ gene. The ends of the plasmid molecule were blunt ended using Klenow polymerase and religated, resulting in plasmid pMUTINXZ. A 670 bp DNA fragment encoding the end of the yacF gene was amplified with oligonucleotides NF2F and NF2R using B. subtiliis strain 168 chromosomal DNA as a template. This fragment was digested with EcoRI and inserted into the EcoRI site of pMUTINXZ, resulting in plasmid pXZ2. Plasmid pXZ2 was then integrated onto the chromosome of strain BCJ363 by a Campbell type event generating strain BCJ366 thereby placing expression of the lys $S$ gene under the control of the IPTG inducible $\mathrm{P}_{\text {spac }}$ promoter. To effect tight control of the $\mathrm{P}_{\text {spac }}$ promoter, replicating plasmid pMap65 [30] that encodes a lacI gene, was transformed into $\mathrm{BCJ} 366$ to produce strain BCJ367.

Strain NF54 was made to assess whether a $B$. subtilis strain expressing a T-box regulated lys $K$ gene was viable. A $1.95 \mathrm{~kb}$ fragment of the $B$. cereus chromosome encoding the lysK promoter, leader region and structural gene was generated by PCR using oligonucleotides NF36F and NF9R. This fragment was digested with EcoRI and cloned into the EcoRI site of plasmid pBCJ102 that has transcriptional terminators flanking the multiple cloning site, to generate plasmid pNF30 [31]. A 2567 bp fragment encoding the lysK promoter, $\mathrm{T}$ box element and 
Table 2 Bacterial strains and plasmids used in this work

\begin{tabular}{|c|c|c|}
\hline Strains, plasmids & Relevant characteristics & Reference or source \\
\hline \multicolumn{3}{|l|}{ Strains } \\
\hline \multicolumn{3}{|l|}{ E. coli } \\
\hline TG-1 & supE hsd $\Delta 5$ thi $\Delta\left(\right.$ lac-proAB) $F^{\prime}[\operatorname{traD} 36]$ & [24] \\
\hline TP611 & recBC hsdR $M^{-}$cyab10pen & {$[25]$} \\
\hline B. cereus 14579 & wild type isolate & [34] \\
\hline \multicolumn{3}{|l|}{ B. subtilis } \\
\hline 168 & $\operatorname{trp} C 2$ & Laboratory stock \\
\hline $1 \mathrm{~A} 717$ & amyE::erm $\mathrm{Em}^{\mathrm{R}}$ & [32] \\
\hline $1 A 765$ & $\operatorname{trpC2}$ lys & {$[35]$} \\
\hline NF33 & 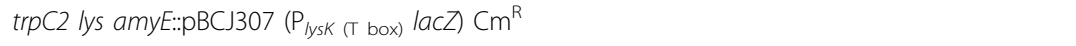 & This study \\
\hline NF52 & $\operatorname{trpC2}$ amyE::pNF48 (P/ysk (T box) lysK) Spec ${ }^{R}$ & This study \\
\hline NF54 & $\operatorname{trpC2}$ amyE:::pNF48 (P/ysk (T box) lysK) Spec ${ }^{R}$ DlysS Kan ${ }^{R}$ & This study \\
\hline NF58 & $\operatorname{trpC2}$ amyE:::pBCJ307 ( $\mathrm{P}_{\text {lysk (T box) }}$ lacZ) $\mathrm{Cm}^{\mathrm{R}}$ asnS::pNF40 (P $\mathrm{P}_{\text {spac }}$ asnS) Em ${ }^{\mathrm{R}}$ & This study \\
\hline NF60 & 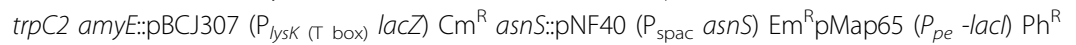 & This study \\
\hline NF113 & $\operatorname{trpC2}$ lysS::.pNF112 ( $\mathrm{P}_{\text {lysk (T box) }}$ lysS) $\mathrm{Cm}^{\mathrm{R}}$ & This study \\
\hline NF204 & $\operatorname{trpC2}$ amyE:::pBCJ307 ( $\mathrm{P}_{\text {lysk (T box) }}$ lacZ) $\mathrm{Em}^{\mathrm{R}} \mathrm{Cm}^{\mathrm{R}}$ & This study \\
\hline NF205 & 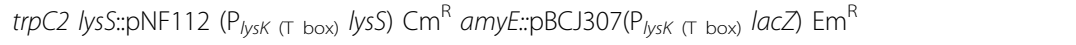 & This study \\
\hline NF206 & 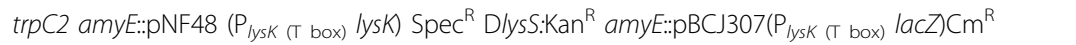 & This study \\
\hline BCJ363 & $\operatorname{trpC2}$ amyE::pBCJ307 ( $\mathrm{P}_{\text {lysk (T box })}$ lacZ) $\mathrm{Cm}^{\mathrm{R}}$ & This study \\
\hline BCJ366 & 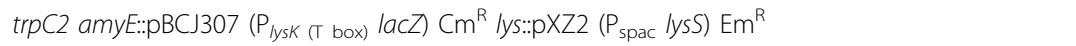 & This study \\
\hline $\mathrm{BCJ} 367$ & 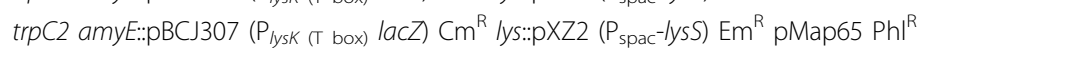 & This study \\
\hline \multicolumn{3}{|l|}{ Plasmids } \\
\hline pBluescript2 KS(-) & cloning vector $A p^{R}$ & Stratagene, La Jolla CA \\
\hline pMutin4 & integration vector for $B$. subtilis & [27] \\
\hline pBCJ102 & pBluescript based vector containing transcription terminator cassettes $A p^{R}$ & [29] \\
\hline pBCJ144 & vector to replace part of $B$. subtilis lysS with $\operatorname{Kan}^{R}$ & {$[29]$} \\
\hline pBCJ307 & vector with transcriptional fusion of $B$. cereus lys $K$ promoter and $T$ box with $l a c Z \mathrm{Cm}^{R}$ & This study \\
\hline pDG268 & vector to generate lacZ promoter fusions at the amyE locus by double crossover $A p^{R} \mathrm{Cm}^{R}$ & [26] \\
\hline pDG1730 & vector for integration at the amyE locus in B. subtilis Spec $^{R}$ & [30] \\
\hline pXZ2 & Vector to placing B. subtilis lysS under control of IPTG inducible Pspac promoter Em ${ }^{R}$ & This study \\
\hline PMUTIN-XZ & pMUTIN4 with the lacZ gene removed $\mathrm{Em}^{\mathrm{R}}$ & This study \\
\hline pMap65 & replicating B. subtilis plasmid encoding penP-lacl $\mathrm{Ph}^{\mathrm{R}} \mathrm{Kan}^{\mathrm{R}}$ & [28] \\
\hline pNF30 & plasmid with B. cereus lysK promoter and T box element in $\mathrm{pBCJ102} \mathrm{Ap}^{\mathrm{R}}$ & This study \\
\hline pNF40 & B. subtilis asnS promoter on $516 \mathrm{bp}$ fragment in $\mathrm{pMUTIN-XZ}$ & This study \\
\hline pNF48 & B. cereus lysK promoter and lysK gene cloned into pDG1730 & This study \\
\hline pNF112 & the lys K promoter and T box element (423 bp) fused to B. subtilis lysS (672 bp fragment) & This study \\
\hline
\end{tabular}

structural gene flanked by transcriptional terminator sequences was amplified using the pBluescript T7 and M13 reverse primers and plasmid pBCJ102 as template. The ends of this fragment were phosphoryalted using T4 polynucleotide kinase (Promega) and it was then cloned into the EcoRV site of plasmid pDG1730 [32] to produce the plasmid pNF48. Plasmid pNF48 was integrated at the $a m y E$ locus of the B. subtilis chromosome by a double crossover event to produce strain NF52. The lysS gene of strain NF52 was then partially deleted by integration of plasmid pBCJ144 [31] into the chromosome by a double-crossover event, replacing part of lys $S$ with a kanamycin resistance cassette, thereby generating strain NF54. In strain NF54, 373 amino acids of LysRS are deleted leaving only the C-terminal 126 amino acids). Importantly, in this strain the $\mathrm{P}_{\text {lys } K \text { (Tbox) }}$ lys $K$ construct is flanked by transcriptional terminators so that lysK expression is solely dependent on the $\mathrm{P}_{l y s K}$ (Tbox) promoter. To insert the $\mathrm{P}_{\text {lysK (Tbox) lac } Z \text { reporter }}$ fusion into the chromosome of B. subtilis strain NF54, plasmid pBCJ307 was integrated at the $a m y E$ locus, thereby generating strain NF206. 
Table 3 Oligonucleotides used in this study

\begin{tabular}{ll}
\hline Primer & Sequence $\left(\mathbf{5}^{\prime}\right.$-3') \\
\hline NF2F & CGGAATTCCAAATGGCTTCTCGATCC \\
NF2R & CGGAATTCGGTGAGTATTATCCTACTITGC \\
NF3R/2 & CGGGATCCGCGTTGGGTGAGTATAAACGG \\
NF9R & CGGAATTCCTTGCGTGCTTTAACTGTGT \\
NF15F & GGTGAGTAATATATGAGTCAAGAAGAGCATAACC \\
NF15R & TTGACTCATATATTACTCACCTCAATTATTITTG \\
NF16F & CCCAAGCTTCTTCTTGTITGGAGGGAATATG \\
NF16R & CCCAAGCTTCCTTCAGGTGCGCTTCCAGTC \\
NF36F & CGGAATTCCGATTCGATTCGGAAAGTTG \\
NF36R & CGGGATCCGCTACTTCATACGCCCAATGC \\
T7 & TAATACGACTCACTATAGGG \\
M13 rev & CAGGAAACAGCTATGACC \\
\hline
\end{tabular}

${ }^{*}$ Added restriction sites are shown in bold.

To construct B. subtilis strain NF113, that has expression of the endogenous lysS gene under the control of the lysK promoter and $\mathrm{T}$ box element, a $423 \mathrm{bp}$ DNA fragment encoding the $B$. cereus lys $K$ promoter and $\mathrm{T}$ box element (generated using oligonucleotides NF36F and NF15R) was fused to a 672 bp fragment of the lys $S$ gene (generated using oligonucleotides NF15F and NF3R/2) by overlapping PCR (using the outside primers NF36F and NF3R/2). This DNA fragment was then digested with EcoRI and BamHI and cloned into EcoRI digested pBCJ102 [31] to generate the plasmid pNF112: the $\mathrm{P}_{l y s K}$ (Tbox) lysS insert is flanked by transcriptional terminators in this plasmid. Plasmid pNF112 was then integrated into the B. subtilis chromosome at the lysS locus by a Campbell-type event to produce the strain NF113. To introduce the $\mathrm{P}_{\text {lysK (Tbox) }}$ lac $Z$ reporter fusion into strain NF113, it was transformed with chromosomal DNA from strain NF204 that contains the $\mathrm{P}_{\text {lysK (Tbox) }}$ lac $Z$ reporter fusion at the $a m y E$ locus, thereby generating strain NF205. Strain NF204 was constructed by transformation of strain 1A717 [32] with pBCJ307. To construct B. subtilis strain NF60 in which expression of the endogenous asn $S$ gene is placed under the control of the IPTG-dependent $\mathrm{P}_{\text {Spac }}$ promoter and containing the $\mathrm{P}_{\text {lys } K \text { (T box })}$ lac $Z$ fusion, a 516 bp DNA fragment encoding the asnS promoter region was amplified using oligonucleotides NF16F and NF16R, digested with HindIII and cloned into HindIII digested pMutinXZ to produce plasmid pNF40. Plasmid pNF40 was transformed into B. subtilis strain BCJ363 by a Campbell-type event to produce strain NF58. Plasmid pMAP65 (encoding the lacI gene) was then established in strain NF58 to ensure strict IPTG-dependent asnS expression, thereby generating strain NF60.

\section{Measurement of tRNA charging by Northern analysis} Establishing the level of charged tRNA ${ }^{\text {Lys }}$ was carried out as previously described [31]. B. subtilis tRNA ${ }^{\text {Lys }}$ was detected with an oligonucleotide probe complementary to nucleotides 26-51 that was labeled either with DIG oligonucleotide Tailing Kit (Roche, East Sussex, UK) or with biotin (New England Biolabs, USA). Detection used either the DIG labeling kit (Roche, East Sussex, UK) or the NEB blot phototope kit (New England Biolabs, USA) according to the manufacturer's instructions.

\section{Determination of $\beta$-galactosidase activity}

Measurement of $\beta$-galactosidase activity was as previously described [33].

\section{Bioinformatic analysis}

The genes encoding AARS proteins were identified in 891 bacterial genomes by homology with their orthologues of B. subtilis - for glutaminyl tRNA synthetases, the $E$. coli protein was used. Only proteins that displayed BLAST E-values of less than $10^{-10}$ were retained for further analysis. The complete upstream region of each AARS-encoding gene was examined for the presence of the T-box motif TGGNACCGCG, allowing up to two mismatches in the last six positions. Sequences containing potential T-box sequences were then examined manually for their ability to form mutually exclusive terminator and anti-terminator DNA structures

\section{Additional material}

Additional file 1: Sequence alignment and putative structures of $T$ box regulatory elements from Bacillus cereus (lysk), Bacillus thuringiensis (lysK), Clostridium beijerinckii (lysS2) and Symbiobacterium thermophilum (lysS). Figure S1 shows a sequence alignment of the $T$ box regulatory elements associated with the lysK genes of $B$. cereus and $B$. thuringiensis. Figure $S 2$ shows a sequence alignment of the T box regulatory elements associated with the lysK gene from $B$. cereus and the lys $\$ 2$ gene from C. beijerinckii. Figure S3 shows a sequence alignment of the $T$ box regulatory elements associated with the lysK gene from B. cereus and the lysS gene from $S$. thermophilum. Figure $S 4$ shows a sequence alignment of the $T$ box regulatory elements associated with the lys $S$ gene from $S$. thermophilum and the lysS gene from C. beijerinckii. Figure S5 shows a putative structure for the $\mathrm{T}$ box regulatory element associated with the lys $K$ gene from $B$. cereus. Figure $S 6$ shows a putative structure of the T box regulatory element associated with the lys 22 gene from C. beijerinckii. Figure S7 shows a putative structure for the T box regulatory element associated with the lys $S$ gene from $S$. thermophilum.

\section{Acknowledgements}

This work was supported by Science Foundation Ireland Principal Investigator Awards (03/IN3/B409 and 08/IN.1/B1859) and by the EU Sixth Framework grant BACELL Health (LSHC-CT-2004-503468).

\section{Author details}

${ }^{1}$ Smurfit Institute of Genetics, Trinity College Dublin, Dublin 2. Ireland. ${ }^{2}$ Institut de Biologie Moléculaire et Cellulaire, 15 Rue René Descartes, 67084 Strasbourg, France. ${ }^{3}$ Division of Animal Sciences and Informatics Institute, University of Missouri, Columbia, MO 65211. USA. 


\section{Authors' contributions}

NF performed the experiments, analyzed the data and contributed to writing the paper, $\mathrm{BCJ}$ performed some experiments and contributed to writing the paper, GC performed the bioinformatic analysis and contributed to writing the paper and KD initiated the study, analyzed the data and contributed to writing the paper.

Received: 5 May 2010 Accepted: 22 July 2010 Published: 22 July 2010

\section{References}

1. Grunberg-Manago M: Regulation of the expression of aminoacyl-tRNA synthetases and translation factors. Escherichia coli and Salmonella. Cellular and Molecular Biology Washington DC: ASM PressNeidhardt FC 1996, 1432-1457.

2. Woese $C R$, Olsen GJ, Ibba M, Söll D: Aminoacyl-tRNA synthetases, the genetic code, and the evolutionary process. Microbiol Mol Biol Rev 2000, 64:202-236.

3. Ibba M, Söll D: The renaissance of aminoacyl-tRNA synthesis. EMBO Rep 2000, 2:382-387.

4. O'Donoghue P, Luthey-Schulten Z: On the evolution of structure in aminoacyl-tRNA synthetases. Microbiol Mol Biol Rev 2003, 67:550-573.

5. Ibba M, Morgan S, Curnow AW, Pridmore DR, Vothknecht UC, Gardner W, Lin W, Woese CR, Söll D: A euryarchaeal lysyl-tRNA synthetase: resemblance to class I synthetases. Science 1997, 278:1119-1122.

6. Ibba M, Bono JL, Rosa PA, Söll D: Archaeal-type lysyl-tRNA synthetase in the Lyme disease spirochete Borrelia burgdorferi. Proc Natl Acad Sci USA 1997, 26:14383-14388.

7. Polycarpo C, Ambrogelly A, Ruan B, Tumbula-Hansen D, Ataide SF, Ishitani R, Yokoyama S, Nureki O, Ibba M, Söll D: Activation of the pyrrolysine suppressor tRNA requires formation of a ternary complex with class I and class II lysyl-tRNA synthetases. Mol Cell 2003, 12:287-94.

8. Ataide SF, Jester BC, Devine KM, Ibba M: Stationary-phase expression and aminoacylation of a transfer-RNA-like small RNA. EMBO Rep 2005, 6:742-747.

9. Ataide SF, Rogers TE, lbba M: The CCA anticodon specifies separate functions inside and outside translation in Bacillus cereus. RNA Biol 2009, 6:479-487.

10. Condon C, Grunberg-Manago M, Putzer H: Aminoacyl-tRNA synthetase gene regulation in Bacillus subtilis. Biochimie 1996, 78:381-389.

11. Putzer H, Gendron N, Grunberg-Manago M: Co-ordinate expression of the two threonyl-tRNA synthetase genes in Bacillus subtilis: control by transcriptional antitermination involving a conserved regulatory sequence. Embo J 1992, 11:3117-3127.

12. Henkin TM, Glass BL, Grundy FJ: Analysis of the Bacillus subtilis tyrS gene: conservation of a regulatory sequence in multiple tRNA synthetase genes. J Bacteriol 1992, 174:1299-1306.

13. Grundy FJ, Henkin TM: tRNA as a positive regulator of transcription antitermination in B. subtilis. Cell 1993, 74:475-482.

14. Green NJ, Grundy FJ, Henkin TM: The T box mechanism: tRNA as a regulatory molecule. FEBS Lett 2010, 584:318-324.

15. Vitreschak AG, Mironov AA, Lyubetsky VA, Gelfand MS: Comparative genomic analysis of T-box regulatory systems in bacteria. RNA 2008, 14:717-735.

16. Wels M, Groot Kormelink T, Kleerebezem M, Siezen RJ, Francke C: An in silico analysis of T-box regulated genes and T-box evolution in prokaryotes, with emphasis on prediction of substrate specificity of transporters. BMC Genomics 2008, 9:330-346.

17. Gutierrez-Preciado A, Henkin TM, Grundy FJ, Yanofsky C, Merino E: Biochemical features and functional implications of the RNA-based Tbox regulatory mechanism. Microbiol Mol Biol Rev 2009, 73:36-61.

18. Grundy FJ, Rollins SM, Henkin TM: Interaction between the acceptor end of tRNA and the T box stimulates antitermination in the Bacillus subtilis tyrS gene: a new role for the discriminator base. J Bacteriol 1994, 176:4518-4526.

19. Henkin TM: tRNA-directed transcription antitermination. Mol Microbiol 1994, 13:381-387.

20. Shaul S, Nussinov R, Pupko T: Paths of lateral gene transfer of lysylaminoacyl-tRNA synthetases with a unique evolutionary transition stage of prokaryotes coding for class I and II varieties by the same organisms. BMC Evol Biol 2006, 6:22-31.
21. Wang S, Praetorius-lbba M, Ataide S, Roy H, Ibba M: Discrimination of cognate and non-cognate substrates at the active site of class I lysyltRNA synthetase. Biochemistry 2006, 45:3646-3652.

22. Anagnostopoulos $C$, Spizizen J: Requirements for transformation in Bacillus subtilis. J Bacteriol 1961, 81:741-746.

23. Stulke J, Hanschke R, Hecker M: Temporal activation of beta-glucanase synthesis in Bacillus subtilis is mediated by the GTP pool. J Gen Microbiol 1993, 139:2041-2045.

24. Gibson JF, Poole RK, Hughes MN, Rees JF: Filamentous growth of Escherichia coli K12 elicited by dimeric, mixed-valence complexes of ruthenium. Arch Microbiol 1984, 139:265-271.

25. Glaser P, Kunst F, Arnaud M, Coudart MP, Gonzales W, Hullo MF, lonescu M, Lubochinsky B, Marcelino L, Moszer I, Presecan E, Santana M, Schneider E, Schwelzer J, Vertes A, Rapoport G, Danchin A: Bacillus subtilis genome project: cloning and sequencing of the $97 \mathrm{~kb}$ region from 325 degrees to 333 degrees. Mol Microbiol 1993, 10:371-384.

26. Sambrook J, Fritsch E, Maniatis T: Molecular Cloning: A Laboratory Manual. Plainview NY: Cold Spring Harbor Laboratory Press 1989.

27. Harwood C, Cutting S: Molecular Biological Methods for Bacillus. NY: Wiley 1990.

28. Antoniewski C, Savelli B, Stragier P: The spollJ gene, which regulates early developmental steps in Bacillus subtilis, belongs to a class of environmentally responsive genes. J Bacteriol 1990, 172:86-93.

29. Vagner $V$, Dervyn $E$, Ehrlich SD: A vector for systematic gene inactivation in Bacillus subtilis. Microbiology 1998, 144:3097-3104.

30. Petit M, Dervyn E, Rose M, Entian K, McGovern S, Ehrlich S, Bruand C: PcrA is an essential DNA helicase of Bacillus subtilis fulfilling functions both in repair and rolling-circle replication. Mol Microbiol 1998, 29:261-273.

31. Jester BC, Levengood JD, Roy H, Ibba M, Devine KM: Nonorthologous replacement of lysyl-tRNA synthetase prevents addition of lysine analogues to the genetic code. Proc Natl Acad Sci USA 2003, 100:14351-14356.

32. Guerout-Fleury A, Shazand K, Frandsen N, Stragier P: Antibiotic-resistance cassettes for Bacillus subtilis. Gene 1995, 180:335-336.

33. Noone D, Howell A, Devine KM: Expression of $y k d A$, encoding a Bacillus subtilis homologue of $\mathrm{HtrA}$, is heat shock inducible and negatively autoregulated. J Bacteriol 2000, 182:1592-1599.

34. Lawrence JS, Ford WW: Studies on aerobic spore-bearing non-pathogenic bacteria. Part 1. J Bacterio/ 1:273-320.

35. Bacillus Genetic Stock Centre. [http://www.bgsc.org].

\section{doi:10.1186/1471-2180-10-196}

Cite this article as: Foy et al:: The T box regulatory element controlling expression of the class I lysyl-tRNA synthetase of Bacillus cereus strain 14579 is functional and can be partially induced by reduced charging of asparaginyl-tRNA ${ }^{\text {Asn }}$. BMC Microbiology 2010 10:196.

\section{Submit your next manuscript to BioMed Central and take full advantage of:}

- Convenient online submission

- Thorough peer review

- No space constraints or color figure charges

- Immediate publication on acceptance

- Inclusion in PubMed, CAS, Scopus and Google Scholar

- Research which is freely available for redistribution 